\title{
BMJ Open Vitamin D supplementation in chronic spinal cord injury (VitD-SCI): study protocol for a randomised controlled trial
}

\author{
Anneke Hertig-Godeschalk (D) , ${ }^{1}$ Martin W G Brinkhof, ${ }^{2,3}$ Anke Scheel-Sailer, ${ }^{3,4}$ \\ Claudio Perret, ${ }^{1}$ Andreas Jenny, ${ }^{4}$ Gunter Landmann, ${ }^{5}$ Patrik O Wyss, ${ }^{6}$ \\ Joelle Leonie Flueck (iD ${ }^{1}$
}

To cite: Hertig-Godeschalk A, Brinkhof MWG, ScheelSailer A, et al. Vitamin D supplementation in chronic spinal cord injury (VitD-SCl): study protocol for a randomised controlled trial. BMJ Open 2021;11:e053951. doi:10.1136/ bmjopen-2021-053951

- Prepublication history and additional supplemental material for this paper are available online. To view these files, please visit the journal online (http://dx.doi.org/10.1136/ bmjopen-2021-053951).

AH-G and MWGB are joint first authors.

Received 31 May 2021 Accepted 29 November 2021

D Check for updates

(c) Author(s) (or their employer(s)) 2021. Re-use permitted under CC BY-NC. No commercial re-use. See rights and permissions. Published by BMJ.

For numbered affiliations see end of article.

\section{Correspondence to} Dr Joelle Leonie Flueck; joelle.flueck@sportmedizinnottwil.ch

\section{ABSTRACT}

Introduction Vitamin $D$ insufficiency, a vitamin $D$ status or serum $25(\mathrm{OH}) \mathrm{D}$ concentration of $\leq 75 \mathrm{nmol} / \mathrm{L}$, is highly prevalent in individuals with a spinal cord injury (SCl). Vitamin D is important for the functioning of the musculoskeletal, immune and respiratory systems, which are relevant determinants of secondary health conditions in SCl. An insufficiency should be treated with vitamin D supplementation. However, there is a lack of evidence regarding the optimal dosage and duration of vitamin D supplementation for individualised and long-term management of the vitamin $\mathrm{D}$ status in the context of $\mathrm{SCl}$. This paper presents the protocol for the vitamin $\mathrm{D}$ supplementation in chronic spinal cord injury (VitD-SCI) trial that aims to investigate the effect of a 12-month intake of vitamin D supplementation on vitamin $D$ status as well as on several secondary parameters among individuals with a chronic SCl. Methods and analyses The VitD-SCl trial is a randomised, placebo-controlled, double-blinded, parallel-group, superiority trial, conducted at the Swiss Paraplegic Centre. A total of 45 participants living with an $\mathrm{SCl}$ for at least 3 years (chronic $\mathrm{SCl}$ ) and a vitamin $\mathrm{D}$ insufficiency at the first study visit, will be randomly assigned to one of three intervention groups. Participants receive either a monthly dosage of $24000 \mathrm{IU}$ or 48 000 IU vitamin D or a placebo for 12 months. Measurements taking place every 3 months include the assessment of vitamin D status (primary outcome) as well as bone mineral density, handgrip strength, fatigue, mood, pain and pressure injuries (secondary outcomes). Safety and tolerance of vitamin D supplementation will also be evaluated.

Ethics and dissemination The Swiss Ethics Committee for Northwest/Central Switzerland (EKNZ, 2020-01493) and the Swiss Agency for Therapeutic Products (Swissmedic, 2020DR3150) approved this study. Findings will be disseminated through peer-reviewed publications. Trial registration numbers NCT04652544 and SNCTP000004032.

\section{INTRODUCTION}

A suboptimal vitamin D status is prevalent in up to $93 \%$ of individuals with spinal cord injury (SCI) which is excessive compared with up to $40 \%$ among the general population. ${ }^{12}$ This excessive prevalence can be explained
Strengths and limitations of this study

- The longitudinal study design facilitates control for within-person and between-person variation in investigating the temporal efficacy of vitamin $D$ supplementation on vitamin $D$ dynamics.

- The recurrent assessment of contextual parameters, including sun exposure and secondary health conditions, for use as time-updated covariates in the data analysis, will further support unbiased inference of the efficacy of vitamin D supplementation.

- The adherence of participants to the protocol cannot be objectively assessed, because of the homebased setting.

- Dietary vitamin D will not be assessed over the study period, which precludes scaling of vitamin D efficacy to between-person and within-person variation in nutrition intake.

- For reasons of feasibility, not all supposedly relevant clinical outcomes can be assessed, including respiratory and immune function.

by the adverse impact of SCI on physiological functioning, including altered metabolism and gastrointestinal functioning, and lifestyle behaviours, such as reduced physical exercise, outdoor activity and sun exposure. ${ }^{13}$ Vitamin D is important for the optimal functioning of the musculoskeletal and respiratory system as well as the regulation of innate and adaptive immune responses. ${ }^{4-9}$ Particularly in the context of SCI, a lower vitamin $\mathrm{D}$ status has been associated with an elevated risk of respiratory illness, pressure injuries and depression, as well as poor physical function and bone mineral density. ${ }^{10-14}$ Therefore, the prevention of a vitamin D insufficiency, commonly defined as a vitamin D status of $75 \mathrm{nmol} / \mathrm{L}$ or less, ${ }^{15}$ is of great concern regarding secondary health conditions in SCI. 
Vitamin D supplementation is a promising intervention to reduce and prevent a vitamin D insufficiency as well as secondary complications, ${ }^{2416}$ yet the provision of such clinical guidelines in the context of SCI is currently hampered by a lack of evidence regarding the efficacy, as well as the optimal dosage and duration of the supplementation. ${ }^{13}$ For the general non-SCI population (adults aged 19-70 years) a dosage of $600 \mathrm{IU}-800 \mathrm{IU} /$ day has been recommended ${ }^{17-19}$ although other experts consider this dosage as suboptimal. ${ }^{20}{ }^{21}$ Among individuals with chronic SCI, a dosage of $800 \mathrm{IU} /$ day for 12 months failed to raise vitamin D status to sufficient levels. ${ }^{22}$ Higher dosages of $2000 \mathrm{IU} /$ day $^{23}$ or $6000 \mathrm{IU} /$ day $^{24}$ during 3 months appeared more successful, but the respective studies did not investigate the long-term efficacy regarding vitamin $\mathrm{D}$ status or the lasting consequences for musculoskeletal and subjective health parameters. Though recommended, ${ }^{25}$ vitamin D status is not regularly monitored among the chronic SCI population.

To close this evidence gap, we present the protocol for the vitamin $\mathrm{D}$ supplementation in chronic spinal cord injury (VitD-SCI) trial: a placebo-controlled randomised controlled trial that investigates the efficacy of a moderate (24 $000 \mathrm{IU} /$ month) and a high (48 $000 \mathrm{IU} /$ month) dosage of vitamin D supplementation for 12 months among individuals living with an SCI for at least 3 years (chronic SCI). Besides vitamin D status (primary objective), further assessments include bone mineral density, fatigue, pain, mood, performance of daily activities and handgrip strength (secondary objectives). We hypothesise a dose-response effect of vitamin $\mathrm{D}$ supplementation on vitamin D status and anticipate that the evidence acquired during this study will effectively inform community-based policy regarding vitamin D supplementation in chronic SCI.

\section{METHODS AND ANALYSES}

\section{Study design and setting}

The VitD-SCI trial is a placebo-controlled randomised double-blinded superiority study, evaluating the effect of 12 months of vitamin D supplementation on vitamin D status and several secondary outcomes among individuals with a chronic SCI (figure 1). This protocol was designed according to the recommendations of the Standard Protocol Items: Recommendations for Interventional Trials 2013 Statement (online supplemental file 1) ${ }^{26}$ The study is planned to run from May 2021 to May 2023. Study visits take place at the Swiss Paraplegic Centre and participants will receive compensation for travel expenses. The VitD-SCI trial is a nested project of the population-based Swiss Spinal Cord Injury (SwiSCI) cohort study. ${ }^{27}$

\section{Patient and public involvement statement}

Patient and public organisations (eg, SwiSCI), as well as clinicians from several specialised SCI centres, have been involved in the design of the study protocol. Study procedures, including the intervention and assessments, have been discussed and tested together with individuals with SCI.

\section{Participants}

The inception cohort of the SwiSCI cohort study (2013present) ${ }^{28}$ provides the sampling frame for participant recruitment for the VitD-SCI trial. Eligible are individuals who provided consent to be contacted for future scientific studies and who fulfil the key VitD-SCI trial inclusion criteria, including a vertebral lesion level of $\mathrm{C} 4$ or below and time since SCI of at least 3 years. At present (May 2021), SwiSCI data indicate a sample of over 300 eligible individuals. Among individuals interested in participating, the remaining eligibility criteria (table 1) will be checked. Women of childbearing age must show a negative pregnancy test at the start of the experimental supplementation and must use adequate contraception during the 12-month treatment phase of the study. Participants are not allowed to take additional vitamin D supplements ( $>400 \mathrm{IU} /$ day) or travel to countries with increased sun exposure (below the 37th parallel north) during the study. No further eligibility criteria, such as the completeness or the lesion level, were set, to allow a generalisation of the study results as well as to increase the feasibility. The recurrent assessment of contextual parameters for use as time-updated covariates in the data analysis will further support unbiased inference of the temporal efficacy of vitamin D supplementation. Informed consent will be obtained from all participants by qualified study employees (online supplemental file 2). A blood sample will be taken to determine vitamin $\mathrm{D}$ status at the first visit (Month 0).

\section{Intervention}

The trial consists of a three-armed intervention that applies a moderate or generally recommended dosage (24 $000 \mathrm{IU}$ vitamin $\mathrm{D} /$ month), and a high dosage (48 $000 \mathrm{IU}$ vitamin $\mathrm{D} /$ month) for comparison to placebo. Both dosages are prescribed in clinical practice and are within safe tolerable upper intake levels of $10000 \mathrm{IU} /$ day. ${ }^{17} 18{ }^{20}$ Previous studies among individuals with SCI implementing even higher dosages of vitamin D supplementation (up to $50000 \mathrm{IU} /$ week) did not report any safety issues. ${ }^{23} 242930$ The present study will further use a biweekly supplementation procedure, which showed superior adherence and accompanying efficacy over daily administration in achieving a sufficient vitamin D status. ${ }^{31}$ The biweekly supplementation schedule is supported by vitamin $\mathrm{D}$ pharmacokinetics, which indicates a half-life of serum $25(\mathrm{OH}) \mathrm{D}$ of up to 3 weeks. ${ }^{32}$

As vitamin $\mathrm{D}$ supplement, the commercially available Vi-De 3 Monthly Dose (Dr. Wild \& Co. AG, Muttenz, Switzerland) will be used. One vial $(5 \mathrm{~mL})$ contains an ethanol solution ( $65 \%$ alcohol by volume) with $600 \mu \mathrm{g}$ cholecalciferol, which corresponds to $24000 \mathrm{IU}$ vitamin $\mathrm{D}_{3}$. The similar ethanol solution without cholecalciferol will be used as a placebo. Both the vitamin $\mathrm{D}_{3}$ supplement as well as the placebo will be filled in identical vials. An 

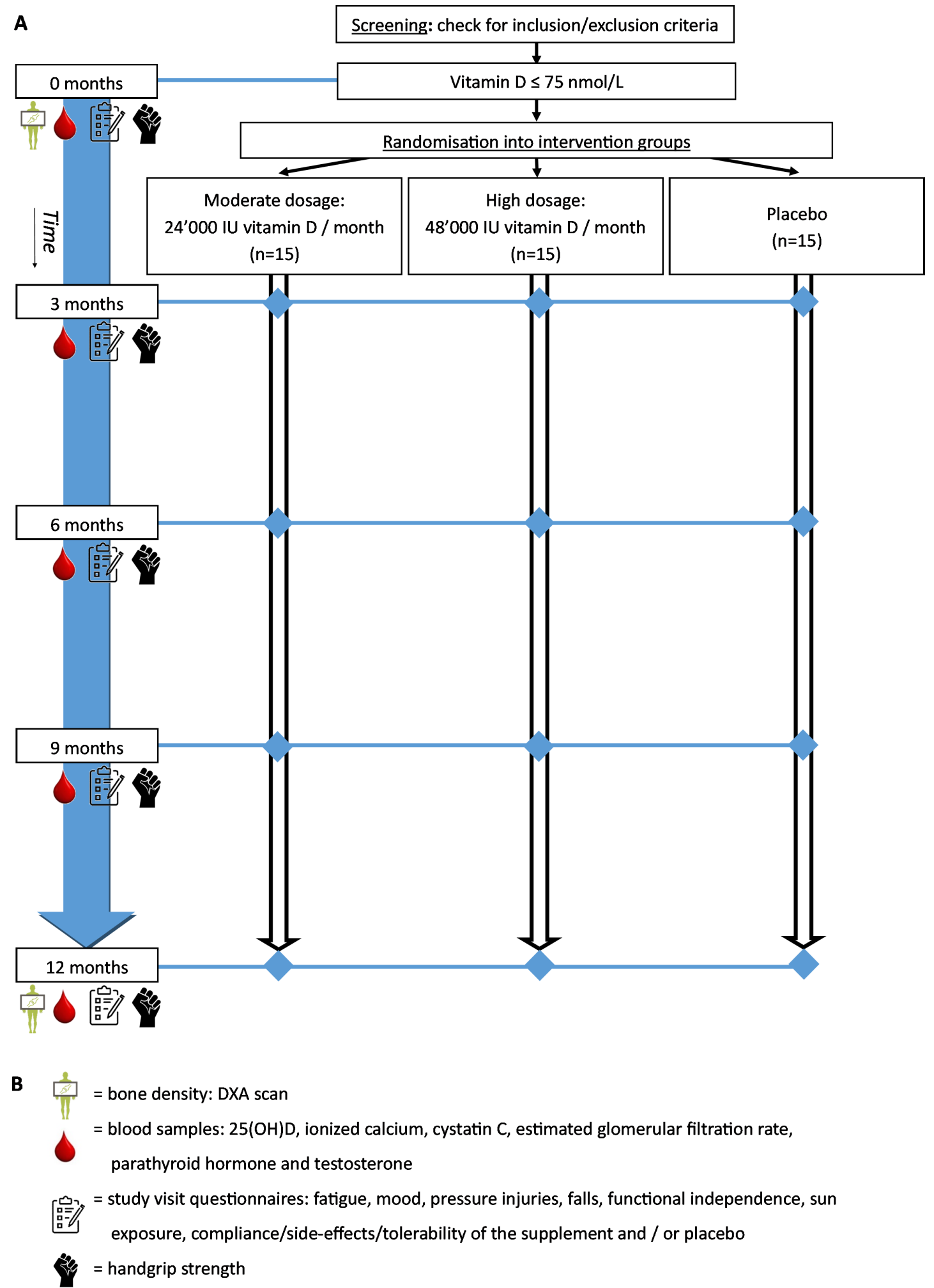

Figure 1 Schematic overview of the study flow. The timeline of the study including the assessments is displayed starting from the screening (top of the figure) to the last study visit (bottom of the figure). (A) Study flow. (B) Legend. DXA, X-ray densitometry.

independent and specialised pharmacy will label the vials with a number that is indicative of the order of intake but indiscriminate regarding content, making the vials indistinguishable in odour, taste and visual appearance. The first vial is to be taken within 7 days after the first study visit. Participants are instructed to ingest one single vial every 2 weeks by emptying the vial in a glass of water and immediately drinking the solution. Participants of the high dosage group will take one vial with 24000 IU vitamin $\mathrm{D}_{3}$ every 2 weeks. Similarly, participants of the placebo group will take one vial with placebo every 2 weeks. Participants of the moderate dosage group will alternately 
Table 1 Eligibility criteria

\section{Inclusion criteria}

- Informed Consent to the study as documented by a signature.

- Chronic (>3 years) traumatic or non-traumatic spinal cord injury a vertebral lesion level of C4 or below.

- Between 18-60 years old.

- Wheelchair dependency during activities of daily living, defined by a score of $0-2$ in the Spinal Cord Independence Measure, subsection 'Mobility in the house'.

- An insufficient vitamin D status $(\leq 75 \mathrm{nmol} / \mathrm{L})$ at the first visit.

\section{Exclusion criteria}

- Contraindications to the investigational product, including known hypersensitivity or allergy to the cholecalciferol or alcohol solution.

- Clinically relevant disorders, including renal dysfunction, hepatic dysfunction, cardiovascular disease, lung disease, diabetes, blood disease, parathyroid disease, cancer, depression, alcohol abuse and/or the intake of significant concomitant medication (including osteoporosis treatment and benzothiadiazide derivatives). This will be assessed on an individual basis.

- Grade 3 or 4 pressure injuries.

- Women who are pregnant or planning to become pregnant during the study period.

- Women who are breast feeding.

- Fractures in both arms and/or both legs within the last 5 years.

- Intake of $>400 \mathrm{IU} /$ day vitamin D supplementation during the last 12 months before recruitment or during the study.

- Visiting a country with increased sun exposure (below the 37 th parallel north, that is, the southern hemisphere) within 1 month before enrolment or during the study.

- Inability to understand or decide on study participation (ie, make an informed consent) and to adhere to the study protocol, for example, due to language or psychological problems. take one vial with $24000 \mathrm{IU}$ vitamin $\mathrm{D}_{3}$ or one vial with placebo every 2 weeks. Thus, an identical number of vials is assured across all intervention groups. The adherence of participants to the protocol cannot be objectively assessed, because the supplement intake occurs at home. To promote compliance with the study protocol, participants will receive a reminder every 2 weeks to take the vials. Participants will also be requested to keep track of the intake of each vial in a study diary and return all (un) used vials to the study centre.

\section{Randomisation and blinding}

Participants will be randomly allocated on a 1:1:1 ratio into one of the three intervention groups, according to a permuted block randomisation list with randomly varying block sizes (three or six) created using the module 'ralloc' $\left(\right.$ V.3.7.6) ${ }^{33}$ within Stata ((computer program), V.16, StataCorp, 2019). The allocation sequence will be securely stored and only accessible to an employee, who is not directly involved in the study. Participants and all study employees directly involved in the recruitment and measurements will be blinded to the assignment of the intervention until the end of the study ('last participant out'). Parameters, such as blood and bone mineral density parameters, which may reveal the allocation across the intervention groups, will only be available to employees who have no direct involvement in the study.

\section{Outcomes and assessments}

Assessment periods and details are specified in table 2. Assessments are performed during screening or each of the 3 monthly visits, except for bone mineral density, which is measured at 0 and 12 months only to reduce radiation exposure. The primary outcome is the differential change in vitamin $\mathrm{D}$ status from 0 to 12 months. Transitional vitamin D status will also be evaluated every 3 months. ${ }^{21}$ The recurrent assessment of contributory parameters, including sun exposure and secondary health conditions, provide time-updated information to statistically control for within-person and betweenperson variation in investigating the efficacy of vitamin D supplementation on vitamin $\mathrm{D}$ dynamics. To evaluate the secondary effects of vitamin D supplementation on the musculoskeletal system, differential changes in the following secondary outcomes will be assessed: relevant blood parameters (calcium, parathyroid hormone, ionised calcium, phosphate, cystatin, estimated glomerular filtration rate, testosterone), bone mineral density, functional independence, pressure injuries, handgrip strength and falls. Differential changes in fatigue, mood and pain will provide insight into the effect of vitamin D supplementation on subjective parameters. Individual parameters, including demographics, SCI characteristics, skin phototype and sun exposure will also be collected. Furthermore, the occurrence of any new illness, injury or disease together with newly taken medication and supplements will be assessed at each visit. Since nutritional 
Table 2 Tools, parameters and timing of the study measurements

\begin{tabular}{|c|c|c|}
\hline Assessment tool & Parameter & Assessment periods \\
\hline \multicolumn{3}{|c|}{ Differential changes in blood parameters (sample taken from the antecubital vein) } \\
\hline Electrochemiluminescence immunoassay & 25(OH)D (nmol/L). & $0 \mathrm{M}, 3 \mathrm{M}, 6 \mathrm{M}, 12 \mathrm{M}$ \\
\hline Photometry-NM-BAPTA & Calcium (mmol/L). & $0 \mathrm{M}, 3 \mathrm{M}, 6 \mathrm{M}, 12 \mathrm{M}$ \\
\hline Potentiometry with ion-selective electrodes & Ionised calcium (mmol/L). & $0 \mathrm{M}, 3 \mathrm{M}, 6 \mathrm{M}, 12 \mathrm{M}$ \\
\hline Chemiluminescence immunoassay (CLIA) & Parathyroid hormone (ng/L). & $0 \mathrm{M}, 3 \mathrm{M}, 6 \mathrm{M}, 12 \mathrm{M}$ \\
\hline Photometry-molybdate ultraviolet & Phosphate (mmol/L). & $0 \mathrm{M}, 3 \mathrm{M}, 6 \mathrm{M}, 12 \mathrm{M}$ \\
\hline $\begin{array}{l}\text { Photometry - particle-enhanced turbidimetric } \\
\text { immunoassay }\end{array}$ & Cystatin C (mg/L). & $0 \mathrm{M}, 3 \mathrm{M}, 6 \mathrm{M}, 12 \mathrm{M}$ \\
\hline Estimated from cystatin C following CKD-EPI and Grubb & Estimated glomerular filtration rate (mL/min). & $0 \mathrm{M}, 3 \mathrm{M}, 6 \mathrm{M}, 12 \mathrm{M}$ \\
\hline CLIA & Testosterone (ng/dL). & $0 \mathrm{M}, 3 \mathrm{M}, 6 \mathrm{M}, 12 \mathrm{M}$ \\
\hline \multicolumn{3}{|l|}{ Differential changes in personal characteristics } \\
\hline Body mass index & From weight and height $\left(\mathrm{kg} / \mathrm{m}^{2}\right)$. & $0 \mathrm{M}, 3 \mathrm{M}, 6 \mathrm{M}, 12 \mathrm{M}$ \\
\hline Sun exposure based on Hanwell et al ${ }^{47}$ & $\begin{array}{l}\text { Time spent outdoors (min) with level of exposed } \\
\text { skin.* }\end{array}$ & $0 \mathrm{M}, 3 \mathrm{M}, 6 \mathrm{M}, 12 \mathrm{M}$ \\
\hline Physical activity & Sport per week (hours and frequency). & $0 \mathrm{M}, 3 \mathrm{M}, 6 \mathrm{M}, 12 \mathrm{M}$ \\
\hline Medication and supplements & Sort and dosage (supplements only). & $0 \mathrm{M}, 3 \mathrm{M}, 6 \mathrm{M}, 12 \mathrm{M}$ \\
\hline Further illnesses & Incidence since last measurement. & $0 \mathrm{M}, 3 \mathrm{M}, 6 \mathrm{M}, 12 \mathrm{M}$ \\
\hline $\begin{array}{l}\text { Skin phototype on the posterior forearm based on } \\
\text { Fitzpatrick }^{48}\end{array}$ & $\begin{array}{l}\text { Six categories ranging from light to very dark skin } \\
\text { types. }\end{array}$ & Screening \\
\hline $\mathrm{SCl}$ characteristics & $\begin{array}{l}\text { Time since SCI (years), neurological level of injury, }{ }^{49} \\
\text { the degree of impairment following the American } \\
\text { Spinal Injury Association Impairment Scale. }{ }^{49}\end{array}$ & Screening \\
\hline
\end{tabular}

Differential changes in bone mineral density

X-ray densitometry, Lunar iDXA Serie with enCORE V.17 T-scores for the forearm (radius), hip (femoral neck) OM, 12M Software and knee (distal femur and proximal tibia).

Differential changes in functional independence

Spinal Cord Independence Measure III $^{50}$

Self-care subscore (0-20), respiration and sphincter

OM, 3M, 6M, 12M management subscore (0-40), indoor mobility subscore (0-10), outdoor mobility subscore (0-30), total score $(0-100)$.

Differential changes in urinary tract infections

Exact questions of the first-wave questionnaire of the Swiss Spinal Cord Injury (SwiSCl) survey ${ }^{27} 51$

Differential changes in pressure injuries

Exact questions of the first-wave questionnaire of the SwiSCl survey ${ }^{27} 51$

incidence since the last measurement, medical care required.

Localisation and grade following the European and

$0 \mathrm{M}, 3 \mathrm{M}, 6 \mathrm{M}, 12 \mathrm{M}$

United States National Pressure Ulcer Advisory panels classification. ${ }^{52}$

Differential changes in pain

Exact questions of the first-wave and second-wave questionnaire of the SwisSCl survey, ${ }^{27}{ }^{51}$ based on the International SCI Pain Basic Data Set ${ }^{53}$ as well as the SCI Secondary Conditions Scale ${ }^{54}$

Differential changes in strength

Jamar Smart Hand Dynamometer (Patterson Medical, Warrenville, Illinois)

The occurrence, kind, location and influence of pain $\quad 0 M, 3 M, 6 M, 12 M$ during the last week as well as chronic pain $(>3$

months).

Three measurements of the left and right hand

OM, 3M, 6M, 12M (mean $\mathrm{kg}$ ).

Differential changes in mood Hospital Anxiety and Depression Scale ${ }^{55}$

Total score (14-56).

$0 \mathrm{M}, 3 \mathrm{M}, 6 \mathrm{M}, 12 \mathrm{M}$

Differential changes in fatigue
Fatigue Severity Scale ${ }^{56}$
Total score (9-63).

$\mathrm{MM}, 3 \mathrm{M}, 6 \mathrm{M}, 12 \mathrm{M}$

Differential changes in falls

Occurrence
Incidence since last measurement, reason daily activity, sport or accident) and medical care required. 
Table 2 Continued

\begin{tabular}{lll}
\hline Assessment tool & Parameter & Assessment periods \\
\hline Safety of the investigational medical products & & The occurrence of life-threatening medical \\
Serious adverse events & complications, the requirement of hospitalisation. & Any time \\
Side effects, tolerability and adherence & $\begin{array}{l}\text { Number of and reason for missed intake, side } \\
\text { effects. }\end{array}$ & OM, 3M, 6M, 12M \\
\hline
\end{tabular}

Assessment periods are referenced to the date of the first visit (OM) and include screening (screening; max 30 days before $0 \mathrm{M})$, 3-month followup (3M; $90 \pm 7$ days), 6-month follow-up (6M; $180 \pm 7$ days) and 12-month follow-up (12M; $365 \pm 7$ days). Serious adverse events are continuously evaluated.

*Level of exposed skin: (1) hands and face, (2) hands, face and arms, (3) hands, face and legs, (4) entire body (bathing suit). CKD-EPI, Chronic Kidney Disease Epidemiology Collaboration; NM-BAPTA, 5-nitro-5'-methyl-(1,2-bis(o-aminophenoxy)ethane-N,N,N’,N'-tetraacetic acid); SCl, spinal cord injury.

intake of vitamin D only accounts for a limited intake and vitamin D fortification of nutrition in Switzerland is rare ${ }^{34}$ no dietary assessments are planned, which precludes scaling of vitamin D efficacy to between-person and within-person variation in nutrition intake. Due to feasibility reasons, no direct measurements of respiratory or immune function will be assessed.

Serious adverse events will be documented throughout the participant's enrolment to evaluate the safety of the supplementation.

\section{Sample size}

We defined the minimal sample size as the sample size needed to detect a statistically meaningful difference in the time course of the primary outcome vitamin D status across the three intervention groups. For this, we estimated the sample size needed to detect an interaction between treatment and time across the three intervention groups using the power analysis package for repeated measures in Stata software, V.16.0 (StataCorp, 2019). The expected mean vitamin $\mathrm{D}$ status at each time point was calculated for each intervention group using the generalised pharmacokinetic curve equation of Heaney, et $a l^{35}$ which we parametrised for the purpose of this study using the available data for vitamin $\mathrm{D}$ supplementation in chronic SCI. ${ }^{23} 36$

Assuming a significance level of $5 \%$ and a power of 0.80 , minimal sample sizes were calculated for a range of between-group variances (ie, 1000-3500, with 500 incremental steps) and correlations between repeated measures (ie, 0.1-0.9, with 0.1 incremental steps; online supplemental file 3). Based on this power analysis for sample size, we conservatively plan for 45 participants with a full data set, implying 15 participants in each of the three intervention groups. In the case of dropouts or a large amount of missing data for a given participant, recruitment will be continued until the minimal sample size of 15 participants per intervention groups is effectively achieved. Sample size calculation did not take secondary outcome parameters into account. Since long-term studies among the chronic SCI population are rare, this study may inform the minimal sample size needed for future studies targeting the dynamics of secondary outcome parameters in response to vitamin D supplementation.

\section{Data management and analyses \\ Data management}

The web browser-based system secuTrial (interActive Systems, Berlin, Germany), which fulfils the Good Clinical Practice requirements, will be used for data capturing and management. This database allows for individualised accounts with predefined roles for each study employee and will be hosted by a study-independent data manager. Built-in quality control mechanisms and notification of missing data will reduce errors during data entry. Participants will be assigned a unique identification code and no directly identifiable information is stored in the database.

\section{Analyses of primary and secondary outcomes}

An intention-to-treat analysis will be performed to prevent potential bias resulting from the distortion of baseline equivalence after randomisation due to the withdrawal of participants, non-adherence to the study protocol, or an unwarranted level of missing data. Participants will only be included in the analyses for which they have data available. Protocol non-adherence, early withdrawals and loss to follow-up will be characterised and examined. Sensitivity analyses using different populations or participant groupings may be used to examine the robustness of the estimator generated by the intention-to-treat analysis. Any sensitivity analyses added after the breaking of the blind (post-hoc sensitivity analyses), including per-protocol analysis that will contain any participants recruited as a replacement for withdrawals or dropouts, will be clearly identified as such in the trial reporting.

Basic univariable statistical analysis techniques will be used to describe the study population as well as the primary and secondary outcomes at the different measurement points. To evaluate the longitudinal variation in the primary outcome and secondary outcomes, multilevel mixed-effects models that appropriately account for the within-individual and between-individual sources of variance in outcome variation will be used. In these models, participants are treated as random effects, while the treatment group is used as a fixed parameter. The choice of 
regression model will depend on the error distribution function of the respective outcome parameter. Timeupdated covariates will also be used in regression modelling, for instance, to evaluate the impact of time-varying vitamin $\mathrm{D}$ status on the secondary outcomes. Time lags in time-updated covariates will also be evaluated to further detail temporal associations. Non-linear regression modelling will be used to evaluate pharmacokinetic curves for each of the intervention groups as described above. Thus, estimates are derived for the parameters $a$ (ie, change is constant at equilibrium), and $k$ (ie, the rate constant for the proportion of the total mass of $25(\mathrm{OH})$ D used or metabolised per day) for mutual comparison as well as with estimates from other populations (other SCI populations, general population or other healthcondition groups).

No interim analyses are planned. If severe clinical deterioration is detected in more than one participant, or on the recommendation of the monitoring committee following a serious adverse event, the study will be suspended until a comprehensive safety review has been completed. If the trial is suspended or halted, an interim analysis will be performed.

\section{Handling of missing data and dropouts}

When appropriate, multiple imputation will be used to account for missing data. ${ }^{37}$ In case the number of dropouts is substantial and systematically related to baseline values of the primary outcome variable, logistic regression modelling will be used to derive inverse probability weights for use in regression modelling to statistically account for potential longitudinal selection bias. Participants who are withdrawn or dropout will be replaced. Sensitivity analysis will be used to address the robustness of the estimators to changes in the assumptions underlying the chosen imputation strategy.

\section{Quality assurance and safety provisions}

\section{Minimising bias and contamination}

Trained study employees will execute all of the measurements following a study manual. Measurement devices will be appropriately serviced and calibrated throughout the study. Questionnaires that have been validated among or adapted for the SCI population will be used. The collection of several possible confounders, including sun exposure, season and SCI level, allows for the correction of these factors. Participants will be asked to express their belief regarding the assigned intervention every 3 months, which will be used to compute a measure for the extent of successful blinding of the trial.

\section{Potential risks}

There are no guidelines regarding upper limits of serum $25(\mathrm{OH}) \mathrm{D}$ concentration among the SCI population, ${ }^{3}$ although vitamin $\mathrm{D}$ toxicity has been reported with levels exceeding 375-750 nmol/L among the general population. ${ }^{38}$ Side effects of vitamin D supplementation, resulting from an overdose, are not expected with the selected dosages in this study. Nevertheless, participants are asked about potential side effects and tolerance of the supplement, and relevant blood parameters will be monitored. Due to the $65 \%$ volume alcohol solution, the intake of the supplement and/or placebo could have a minor influence on the ability to drive or operate machines, but similar solutions have been proven harmless. ${ }^{39}$ The sum of the radiation exposure for the two bone mineral density measurements in this study is less than the average yearly radiation exposure due to radon in Switzerland and falls well within the dose guidance value for Swiss research projects. ${ }^{40} 41$ Serious adverse events will be documented and reported to the local authorities for the entire study duration, which encompasses the signing of the informed consent until the completion of the last protocol-specific procedure including a safety follow-up period. A riskedadapted monitoring ${ }^{42}$ will be applied and executed by the clinical trial unit of the study centre.

\section{Withdrawal criteria}

Participants can withdraw from the study at any time, without providing reasoning. Participants might be redrawn from the study in case of protocol non-adherence, the eligibility criteria are no longer fulfilled or health problems related to the intake of the vitamin $\mathrm{D}_{3}$ supplement or placebo, including a vitamin $\mathrm{D}$ intoxication (serum $25(\mathrm{OH}) \mathrm{D}$ concentration $>375 \mathrm{nmol} / \mathrm{L}$ ) or hypercalcaemia (ionised calcium concentration $>3.5 \mathrm{mmol} / \mathrm{L}$ ).

\section{Unblinding procedures}

The study physician together with the study employees will make study termination and unblinding decisions. Unblinding will only be allowed in the following circumstances; on study termination, in the case of premature study termination or in the case of emergencies or complications. An employee not directly involved in the measurements will perform the unblinding of individual participants during the study. Since each participant receives an individual batch of vials, revealing the blinding for one participant will not unblind the entire cohort.

\section{ETHICS AND DISSEMINATION \\ Ethics approval}

This study will be conducted in compliance with the current version of the Declaration of Helsinki ${ }^{43}$ and the International Conference on Harmonisation Good Clinical Practice guidelines, ${ }^{44}$ as well as all national legal and regulatory requirements. ${ }^{45}$ Both the Swiss Ethics Committee for Northwest/Central Switzerland (EKNZ, 2020-01493) and the Swiss Agency for Therapeutic Products (Swissmedic, 2020DR3150) have approved the study. The study has been registered at ClinicalTrials.gov (NCT04652544). After trial registration, we discovered not all of the secondary and further outcome parameters were mentioned in the registry, the missing outcome parameters were added subsequently. The regulatory 
authorities will receive safety and interim reports and will be informed about protocol changes and the study end.

\section{Dissemination policy}

Results will be published in peer-reviewed journals and presented at scientific conferences. When desired, individual study results will be shared with the participants after the study end. Dissemination among persons with SCI in Switzerland will be achieved through the newsletters 'Paraplegie' and 'Paracontact' as well as through online media. Data and statistical code will be made available on request.

\section{Trial status}

This publication is based on version 3 of the VitD-SCI trial protocol dated 9 November 2020. The official start of recruitment was on 19 May 2021 and data collection is estimated to end on 31 May 2023. As of the time of submission, temporary interruptions due to the COVID-19 pandemic are a possibility and in case of extended disruption, a schedule adjustment may be required.

\section{DISCUSSION}

This is the first study to investigate a 12-month vitamin D supplementation among individuals with a chronic SCI. The existing studies lack the combination of long-term vitamin D supplementation with different dosages, while not only assessing vitamin $\mathrm{D}$ status but also secondary outcomes.

The VitD-SCI trial, for which the protocol is presented here, will provide valuable insights to optimise individual vitamin $\mathrm{D}$ supplementation. If a positive relation between a sufficient vitamin D status and secondary outcomes can be established, this could lead the way for standardised clinical recommendations for long-term management of vitamin $\mathrm{D}$ status and vitamin $\mathrm{D}$ supplementation among the chronic SCI population.

\section{Author affiliations \\ ${ }^{1}$ Institute of Sports Medicine, Swiss Paraplegic Centre, Nottwil, Switzerland \\ ${ }^{2}$ Swiss Paraplegic Research, Nottwil, Switzerland \\ ${ }^{3}$ Department of Health Sciences and Medicine, University of Lucerne, Luzerne, \\ Switzerland \\ ${ }^{4}$ Department of Rehabilitation, Swiss Paraplegic Centre, Nottwil, Switzerland \\ ${ }^{5}$ Centre for Pain Medicine, Swiss Paraplegic Centre, Nottwil, Switzerland \\ ${ }^{6}$ Department of Radiology, Swiss Paraplegic Centre, Nottwil, Switzerland}

Acknowledgements The authors wish to thank Nadine Hunkeler, Beatrice Willi and Yvonne Häberli for their support in the conceptualisation of this protocol.

Contributors JLF is responsible for overseeing the trial. JLF, CP and MWGB were responsible for the study conception and obtained funding. JLF, CP, MWGB, AS-S and $A H-G$ designed the protocol. AS-S provided clinical expertise and is the study physician and principal investigator. POW provided expertise on bone mineral density. MWGB provided statistical expertise. AJ provided clinical expertise on blood parameters and analyses. GL provided clinical expertise on pain outcomes. AH-G, MWGB and JLF prepared the first draft of the manuscript. All authors reviewed and revised the manuscript before submission and approved its content.

Funding The Swiss Paraplegic Centre is the primary funder of this study (no grant number). To develop the study as a nested project of the SwiSCI cohort study, additional funding was achieved by the Swiss Paraplegic Foundation (no grant number). The supplements and the placebo are provided free of charge (no grant number) by Dr. Wild \& Co. AG (Muttenz, Switzerland). Neither funding body had (or will have) a role in the study design; collection, management, analyses and interpretation of data or writing of the publications.

Competing interests None declared.

Patient consent for publication Not applicable.

Provenance and peer review Not commissioned; externally peer reviewed.

Supplemental material This content has been supplied by the author(s). It has not been vetted by BMJ Publishing Group Limited (BMJ) and may not have been peer-reviewed. Any opinions or recommendations discussed are solely those of the author(s) and are not endorsed by BMJ. BMJ disclaims all liability and responsibility arising from any reliance placed on the content. Where the content includes any translated material, BMJ does not warrant the accuracy and reliability of the translations (including but not limited to local regulations, clinical guidelines, terminology, drug names and drug dosages), and is not responsible for any error and/or omissions arising from translation and adaptation or otherwise.

Open access This is an open access article distributed in accordance with the Creative Commons Attribution Non Commercial (CC BY-NC 4.0) license, which permits others to distribute, remix, adapt, build upon this work non-commercially, and license their derivative works on different terms, provided the original work is properly cited, appropriate credit is given, any changes made indicated, and the use is non-commercial. See: http://creativecommons.org/licenses/by-nc/4.0/.

\section{ORCID iDs}

Anneke Hertig-Godeschalk http://orcid.org/0000-0002-4337-3865

Joelle Leonie Flueck http://orcid.org/0000-0002-6401-4490

\section{REFERENCES}

1 Flueck JL, Perret C. Vitamin D deficiency in individuals with a spinal cord injury: a literature review. Spinal Cord 2017;55:428-34.

2 Amrein K, Scherkl M, Hoffmann M, et al. Vitamin D deficiency 2.0: an update on the current status worldwide. Eur J Clin Nutr 2020;74:1498-513.

3 Lamarche J, Mailhot G. Vitamin D and spinal cord injury: should we care? Spinal Cord 2016;54:1060-75.

4 Cranney A, Horsley T, O'Donnell S, et al. Effectiveness and safety of vitamin D in relation to bone health. Evid Rep Technol Assess 2007;158:1-235.

5 Ceglia L, Harris SS. Vitamin D and its role in skeletal muscle. Calcif Tissue Int 2013;92:151-62.

6 Holick MF, Chen TC. Vitamin D deficiency: a worldwide problem with health consequences. Am J Clin Nutr 2008;87:1080S-6.

7 Beard JA, Bearden A, Striker R. Vitamin D and the anti-viral state. J Clin Virol 2011;50:194-200.

8 Jolliffe DA, Camargo CA, Sluyter JD, et al. Vitamin D supplementation to prevent acute respiratory infections: systematic review and meta-analysis of aggregate data from randomised controlled trials. medRxiv 2020. doi:10.1101/2020.07.14.20152728. [Epub ahead of print: 25 Nov 2020] (published Online First: 2020/12/04).

9 Peterlik M, Cross HS, Vitamin D. Vitamin D and calcium insufficiencyrelated chronic diseases: molecular and cellular pathophysiology. Eur $J$ Clin Nutr 2009;63:1377-86.

10 Zhou XJ, Vaziri ND, Segal JL, et al. Effects of chronic spinal cord injury and pressure ulcer on 25(OH)-vitamin D levels. J Am Paraplegia Soc 1993;16:9-13.

11 Barbonetti A, Sperandio A, Micillo A, et al. Independent association of vitamin D with physical function in people with chronic spinal cord injury. Arch Phys Med Rehabil 2016;97:726-32.

12 Barbonetti A, Cavallo F, D'Andrea S, et al. Lower vitamin D levels are associated with depression in people with chronic spinal cord injury. Arch Phys Med Rehabil 2017;98:940-6.

13 Lussi C, Frotzler A, Jenny A, et al. Nutritional blood parameters and nutritional risk screening in patients with spinal cord injury and deep pressure ulcer-a retrospective chart analysis. Spinal Cord 2018;56:168-75.

14 Clark K, Goldstein RL, Hart JE, et al. Plasma vitamin D, past chest illness, and risk of future chest illness in chronic spinal cord injury (SCl): a longitudinal observational study. Spinal Cord 2020;58:504-12.

15 Vieth R. Why the minimum desirable serum 25-hydroxyvitamin D level should be $75 \mathrm{nmol} / \mathrm{L}(30 \mathrm{ng} / \mathrm{ml})$. Best Pract Res Clin Endocrinol Metab 2011;25:681-91.

16 Bischoff-Ferrari HA, Willett WC, Wong JB, et al. Prevention of nonvertebral fractures with oral vitamin $\mathrm{D}$ and dose dependency: 
a meta-analysis of randomized controlled trials. Arch Intern Med 2009;169:551-61.

17 Institute of medicine (IOM). Dietary reference intakes for calcium and vitamin $D$. Washington (dC): the National academies press, 2011.

18 Holick MF, Binkley NC, Bischoff-Ferrari HA, et al. Evaluation, treatment, and prevention of vitamin D deficiency: an endocrine Society clinical practice guideline. J Clin Endocrinol Metab 2011;96:1911-30.

19 Deutsche Gesellschaft für Ernährung ÖGfE, Schweizerische Gesellschaft für Ernährungsforschung. Referenzwerte für die Nährstoffzufuhr vitamin D. Weinstraße: Neuer Umschau Buchverlag, 2012.

20 Hathcock JN, Shao A, Vieth R, et al. Risk assessment for vitamin D. Am J Clin Nutr 2007;85:6-18.

21 Vieth R, Chan PC, MacFarlane GD. Efficacy and safety of vitamin D3 intake exceeding the lowest observed adverse effect level. Am J Clin Nutr 2001;73:288-94.

22 Bauman WA, Morrison NG, Spungen AM. Vitamin D replacement therapy in persons with spinal cord injury. J Spinal Cord Med 2005;28:203-7.

23 Bauman WA, Emmons RR, Cirnigliaro CM, et al. An effective oral vitamin $D$ replacement therapy in persons with spinal cord injury. $J$ Spinal Cord Med 2011;34:455-60.

24 Flueck JL, Schlaepfer MW, Perret C. Effect of 12-Week Vitamin D Supplementation on 25[OH]D Status and Performance in Athletes with a Spinal Cord Injury. Nutrients 2016;8. doi:10.3390/nu8100586. [Epub ahead of print: 22 Sep 2016].

25 Oleson CV, Patel PH, Wuermser L-A. Influence of season, ethnicity, and chronicity on vitamin $\mathrm{D}$ deficiency in traumatic spinal cord injury. J Spinal Cord Med 2010;33:202-13.

26 Chan A-W, Tetzlaff JM, Altman DG, et al. Spirit 2013 statement: defining standard protocol items for clinical trials. Ann Intern Med 2013;158:200-7.

27 Post MWM, Brinkhof MWG, von Elm E, et al. Design of the Swiss spinal cord injury cohort study. Am J Phys Med Rehabil 2011;90:S5-16.

28 Fekete C, Gurtner B, Kunz S, et al. Inception cohort of the Swiss spinal cord injury cohort study (SwiSCl): design, participant characteristics, response rates and non-response. J Rehabil Med 2021;53:jrm00159.

29 Amorim S, Teixeira VH, Corredeira R, et al. Creatine or vitamin D supplementation in individuals with a spinal cord injury undergoing resistance training: a double-blinded, randomized pilot trial. J Spinal Cord Med 2018;41:471-8.

30 Pritchett K, Pritchett RC, Stark L, et al. Effect of Vitamin D Supplementation on 25(OH)D Status in Elite Athletes With Spinal Cord Injury. Int J Sport Nutr Exerc Metab 2019;29:18-23.

31 Dalle Carbonare L, Valenti MT, Del Forno F, et al. Vitamin D: daily vs. monthly use in children and Elderly-What is going on? Nutrients 2017;9. doi:10.3390/nu9070652. [Epub ahead of print: 24 Jun 2017].

32 Lips P. Vitamin D deficiency and secondary hyperparathyroidism in the elderly: consequences for bone loss and fractures and therapeutic implications. Endocr Rev 2001;22:477-501.

33 RALLOC: Stata module to design randomized controlled trials [program], 2018. Available: https://ideas.repec.org/c/boc/bocode/ s319901.html

34 Bundesamt für Lebensmittelsicherheit und Veterinärwesen. Fachinformation zu vitamin D, 2017. Bern. Available: https://www. blv.admin.ch/dam/blv/de/dokumente/lebensmittel-und-ernaehrung/ ernaehrung/fachinformation-vitamin-d.pdf.download.pdf/ fachinformation-vitamin-d.pdf

35 Heaney RP, Davies KM, Chen TC, et al. Human serum 25-hydroxycholecalciferol response to extended oral dosing with cholecalciferol. Am J Clin Nutr 2003;77:204-10.

36 Bauman WA, Zhong YG, Schwartz E. Vitamin D deficiency in veterans with chronic spinal cord injury. Metabolism 1995;44:1612-6.
37 Sterne JAC, White IR, Carlin JB, et al. Multiple imputation for missing data in epidemiological and clinical research: potential and pitfalls. BMJ 2009;338:b2393.

38 Jones G. Pharmacokinetics of vitamin D toxicity. Am J Clin Nutr 2008;88:582S-6.

39 Franz E. Vitamin D Im Säuglingsalter-alkoholische Oder ölige Tropfen? Pharmajournal 2007;12:5-7 https://www.pharmawiki.ch/ wiki/index.php?wiki=Vitamin\%20D\%20f\%C3\%BCr\%20S\%C3\% A4uglinge

40 The Swiss Federal Council. Radiological protection ordinance (RPo), 2017. Available: https://www.fedlex.admin.ch/eli/cc/2017/502/en

41 Bundesamt für Gesundheit (BAG). Strahlenexposition der schweizer bevölkerung, 2018. Available: https://www.bag.admin.ch/bag/ de/home/gesund-leben/umwelt-und-gesundheit/strahlungradioaktivitaet-schall/strahlung-gesundheit/strahlenexposition-derschweizer-bevoelkerung.html\#

42 Brosteanu O, Schwarz G, Houben P, et al. Risk-adapted monitoring is not inferior to extensive on-site monitoring: results of the ADAMON cluster-randomised study. Clin Trials 2017;14:584-96.

43 World Medical Association (WMA). Declaration of Helsinki - ethical principles for medical research involving human subjects, 1964. Available: https://www.wma.net/policies-post/wma-declaration-ofhelsinki-ethical-principles-for-medical-research-involving-humansubjects/

44 Dixon JR. The International Conference on harmonization good clinical practice guideline. Quality Assurance 1999;6:65-74.

45 The Federal Assembly of the Swiss Confederation. Federal act on research involving human beings (human research act, HRA), 2011. Available: https://www.fedlex.admin.ch/eli/cc/2013/617/en

46 The Swiss Federal Council. Ordinance on clinical trials in human research (clinical trials ordinance, ClinO), 2013. Available: https:// fedlex.data.admin.ch/filestore/fedlex.data.admin.ch/eli/cc/2013/ 643/20180424/en/pdf-a/fedlex-data-admin-ch-eli-cc-2013-64320180424-en-pdf-a.pdf

47 Hanwell HEC, Vieth R, Cole DEC, et al. Sun exposure questionnaire predicts circulating 25 -hydroxyvitamin $D$ concentrations in Caucasian Hospital workers in southern Italy. J Steroid Biochem Mol Biol 2010;121:334-7.

48 Fitzpatrick TB. "Soleil et peau" [Sun and skin]. Journal de Medecine Esthetique 1975;2:33-4 https://www.scienceopen.com/document? vid=22582ebe-5f5b-4444-95d8-667d0d4d0954

49 Kirshblum SC, Burns SP, Biering-Sorensen F, et al. International standards for neurological classification of spinal cord injury (revised 2011). J Spinal Cord Med 2011;34:535-46.

50 Itzkovich M, Gelernter I, Biering-Sorensen F, et al. The spinal cord independence measure (SCIM) version III: reliability and validity in a multi-center International study. Disabil Rehabil 2007;29:1926-33.

51 Brinkhof MWG, Fekete C, Chamberlain JD, et al. Swiss national community survey on functioning after spinal cord injury: protocol, characteristics of participants and determinants of non-response. $J$ Rehabil Med 2016;48:120-30.

52 National pressure ulcer Advisory panel EPUAPaPP, alliance. Pi. prevention and treatment of pressure ulcers: quick reference guide. Osborne Park, Australia: Cambridge media, 2014.

53 Widerström-Noga E, Biering-Sørensen F, Bryce T, et al. The International spinal cord injury pain basic data set. Spinal Cord 2008;46:818-23.

54 Kalpakjian CZ, Scelza WM, Forchheimer MB, et al. Preliminary reliability and validity of a spinal cord injury secondary conditions scale. J Spinal Cord Med 2007;30:131-9.

55 Zigmond AS, Snaith RP. The hospital anxiety and depression scale. Acta Psychiatr Scand 1983;67:361-70.

56 Krupp LB, LaRocca NG, Muir-Nash J, et al. The fatigue severity scale. application to patients with multiple sclerosis and systemic lupus erythematosus. Arch Neurol 1989;46:1121-3. 